\title{
LA ETNOGRAFÍA DEL ESTADO EN LA ESCUELA DE MANCHESTER ${ }^{1}$
}

\section{LEIF KORSBAEK*}

\section{Introducción}

La discusión respecto de la etnografía del Estado en la Escuela de Manchester es, al mismo tiempo, relevante, necesaria, ineludible y también difícil. Antes de presentar las virtudes y las dificultades de esta empresa deseo mencionar algunos comentarios, a título de aclaración y tomando en consideración la situación latinoamericana.

La Escuela de Manchester, poco conocida en América Latina y el mundo hispanohablante, al mismo tiempo que forma parte de la tradición británica en la antropología, ha desarrollado una serie de intereses particulares y enfoques especiales. No es solamente, como se piensa por lo regular, una escuela de antropología, sino de antropología y sociología, y tiene, como es el caso de la mayor parte de las "escuelas", contactos con muchas otras disciplinas, como la politología, la psicología, la filosofía, entre otras.

Pero esta amplitud tiene también sus limitaciones. Los antropólogos que se dedican a la antropología política raras veces estudian antropológicamente la economía y, viceversa, los especialistas en la antropología económica solo en escasas ocasiones invierten su tiempo en el estudio de la política. Este hecho lo vemos reflejado en la obra de los dos padres fundadores de la antropología social británica, Bronislaw Malinowski y A. R. Radcliffe-Brown, pues mientras que el primero es conocido como un gran antropólogo económico, con su obra maestra Los argonautas del Pacífico Occidental, el segundo, la eminencia gris detrás de African Political Systems, apenas se acercó al estudio antropológico de la economía. En concordancia con ello, la Escuela de Manchester, que en gran medida debe su fama a sus incursiones en la antropología política, solamente cuenta con una muy tenue presencia en el terreno de la antropología económica, un hecho que ya se vislumbra en la biografía del fundador de la Escuela de Manchester, el antropólogo Max Gluckman.

Entre los intereses particulares que ha desarrollado la Escuela de Manchester, y que la distingue de otras "escuelas", dos son relevantes: el Estado y la estructura. Es la intención, en este texto discutir, algunos de los problemas medulares relacionados con el estudio etnográfico del Estado.

Soy antropólogo y la visión que aquí presento es una visión antropológica. La antropología es una "disciplina de la cual existe una abundancia 
de definiciones, muchas de ellas incompatibles ${ }^{2}$. Sin embargo, los siguientes rasgos actúan como un denominador común: 1) es una disciplina cuyo concepto fundamental es el de "cultura"; 2) es la única disciplina dedicada explícitamente al estudio de la alteridad, más exactamente al estudio de la articulación entre la tradición y la modernidad; 3) recoge su información por medio del trabajo de campo, conocido también como etnografía, y 4) mantiene su ambición holística (Korsbaek, 2009a).

\section{La Escuela de Manchester}

La Escuela de Manchester, nacida en la Universidad de Victoria en Manchester, es, en gran medida, la creación de Max Gluckman. Se relaciona con la entonces colonia británica Rhodesia del Norte, ahora Zambia, donde nació, en 1938, como el Instituto Rhodes-Livingstone $^{3}$, bajo la dirección del antropólogo Godfrey Wilson. Este era un idealista poco diplomático y muy pronto se confrontó con las autoridades coloniales racistas ${ }^{4}$. Le sucedió en el sillón Max Gluckman, un antropólogo británico de familia rusa que se había establecido en Sudáfrica escapando de las revoluciones de su país de origen.

En 1947, Max Gluckman renuncia a la dirección del Instituto Rhodes-Livingstone y viaja a Inglaterra, invitado por su amigo Evans-Pritchard para ocupar una plaza en la Universidad de Oxford. Al poco tiempo de su llegada fue invitado a fundar un departamento de antropología y sociología en la Universidad de Victoria en Manchester. Cabe mencionar que el nombre "Escuela de Manchester" no fue un título formulado por Max Gluckman o sus colaboradores, sino una etiqueta inventada por Mary Douglas (Douglas, 1959).
La creación del departamento de antropología y sociología en Manchester era parte del proyecto académico del gobierno británico, en aquel entonces involucrado en la creación del Estado de bienestar. En ese momento existían pocas universidades que impartieran antropología. Fundamentalmente lo hacían las universidades de Oxford y Cambridge, viejas universidades tradicionales con una fuerte tendencia a la derecha; la Universidad de Londres, que había sido marginada por su afiliación a la teoría difusionista, y la London School of Economics, una escuela reciente, vinculada más a la izquierda y creada en 1895 por el movimiento izquierdista no revolucionario de los Fabians. De esta manera, la nueva escuela de antropología y sociología sería una importante adición a la flora y fauna académica (y política) en Inglaterra.

Quisiera resumir las características de la Escuela de Manchester recordando que esta nunca se distanció de la tradición británica, aun criticándola. Su marco teórico es la sociedad plural, una sociedad que "contiene múltiples poblaciones étnicas dentro de una economía compartida y un orden político centralizado dominado por uno de los grupos". Esta es una situación mucho más común de lo que se piensa: "muchos especialistas comienzan ahora con la noción de que el pluralismo existe, en mayor o menor medida, en todas las sociedades" (MacDonald, 2000, pp. 490, 491). Por otra parte, su método es variado y considera el análisis situacional, el método del caso extendido y el drama social (Korsbaek, 2016c).

Se trata de una escuela con una posición política hacia la izquierda, por lo cual he señalado que "la antropología de Max Gluckman es todo lo contrario del funcionalismo que se le había enseñado en la universidad, más preci- 
samente, podemos decir que la antropología anti-funcionalista de Max Gluckman es la teoría marxista traducida a la antropología, sin el uso de la terminología marxista o la 'jerga' marxista, si así se prefiere" (Korsbaek, 2009b, p. 25). Los funcionalistas británicos ortodoxos (es decir, los alumnos de Malinowski y Radcliffe-Brown), al contrario, nunca se les ocurrió dirigir su atención hacia el Estado colonial, dentro del cual se encontraban sus idílicos Estados primitivos, pues "la antropología clásica ha ignorado o bien no ha tenido bastante en cuenta la situación colonial" (Forster, 1973, p. 11).

Es importante recordar que la Escuela de Manchester pertenece a la tradición británica de la antropología y que en esta tradición hay diversos enfoques, de los cuales quisiera distinguir dos. Por un lado, S. F. Nadel señala que la antropología sive para entender las culturas "primitivas", pero no para entender "nuestra propia civilización, que conocemos un millón de veces mejor y de la que tenemos datos abundantes y adecuados" (Nadel, 1955, p. 12). Por otro lado tenemos a Mary Douglas, de quien se indica que "lo que tiene Douglas de verdaderamente radical es que aplica el mismo diagnóstico para nosotros que para ellos" (Lindholm, 2000, p. 174). La Escuela de Manchester pertenece definitivamente al segundo enfoque.

Aparte de la tradicional caja de herramientas de la antropología social británica, la Escuela de Manchester desarrolla dos temas particulares: por un lado, dirige su atención hacia el uso de la libertad individual en su navegación entre las estructuras y, por el otro, lo hace hacia el Estado.

Es la intención, en este texto, rastrear las descripciones y el análisis del Estado realizados desde la antropología de la Escuela de Manchester y comparar sus producciones con otros trabajos antropológicos. Pero, como es costumbre en este tipo de quehaceres académicos, para discutir la importancia de la etnografía del Estado intentaremos justificar nuestro interés por este.

\section{El Estado}

Pierre Bourdieu advierte contra un peligro que amenaza al observar, pensar y describir el Estado: "atreverse a pensar acerca del Estado es asumir el riesgo de adoptar (o ser adoptado por) un pensamiento del Estado, o sea, aplicar categorías de pensamiento del Estado creadas por el Estado y garantizadas por el Estado, y así perder de vista su verdad más profunda", y ahonda: "una de las principales fuerzas del Estado es producir e imponer (sobre todo a través del sistema de educación) categorías de pensamiento que aplicamos espontáneamente a todas las cosas del mundo social-incluyendo al Estado mismo" (Bourdieu, 1994, p.11).

A esto se suma una complicación más, a la que nos introdujo un sociólogo hace ya algunos años:

El Estado no es la realidad que se encuentra detrás de la máscara de la práctica política. Es él mismo la máscara que no nos permite ver la práctica política tal como es. Hay un sistema estatal: un nexo palpable de prácticas y estructura institucional centrada en el gobierno y más o menos extensivo, unificado y dominante en cualquier sociedad dada. Hay también una idea-Estado, proyectada, proporcionada $y$, en diferentes grados, creída en distintas sociedades en diversos momentos. Solo nos creamos complicaciones al suponer que tenemos también que estudiar al Estado -una entidad, agente, función o relación más allá del sistema estatal y la idea-Estado. El Estado llega a existir como una estructuración y como parte de la práctica política; inicia su vida como un constructo implícito, y luego es reificado -como la res pública- y adquiere una clara identidad simbólica, poco a poco 
divorciado de la práctica como un relato ilusorio. La función ideológica es extendida hasta un punto en el cual tanto los conservadores como los radicales creen que su práctica no está dirigida contra la otra parte sino contra el Estado. La tarea del sociólogo es desmitificar, lo que en el presente contexto significa atender a los sentidos en los cuales el Estado no existe (Abrams, 1988 , p. 58).

Con estas complicaciones, la tarea de describir y entender el Estado se asemeja a la burla que nos ofrece mi paisano Soeren Kierkegaard en su tesis doctoral de 1843, en la que habla sobre la tarea de observar y describir la ironía en la obra de Sócrates como equivalente a hacer un dibujo de un duende con el sombrero que lo hace invisible (Kierkegaard, 1906).

Con todas esas dudas, nebulosidades y opacidades, el Estado ha sido estudiado desde varios ángulos: por historiadores, sociólogos, jurisprudentes y psicólogos, siempre partiendo de la suposición de su realidad y existencia, agregando, cada estudio, conocimientos especializados y parciales.

Los historiadores llaman nuestra atención sobre la existencia de un buen número de tipos de Estados, con sus características y su propio dinamismo. Algunos de ellos se han dedicado a comparar los diversos tipos de Estado. Uno de esos estudios comparativos es Los orígenes sociales de la dictadura y la democracia (Moore, 1973), en el cual se contraponen tres sociedades occidentales: Inglaterra, Francia y los Estados Unidos, con tres sociedades orientales: China, Japón e India. También hay otra obra, El Estado absolutista (Anderson, 1980), que me parece pertinente citar, que es menos panorámica y más específica, y que se limita a estudiar el desarrollo del Estado despótico comparando su desenvolvimiento en tres macrorregiones: en
Europa occidental (España, Francia, Inglaterra, Italia y Suecia); en Europa oriental (Prusia, Polonia, Austria y Rusia, aparte de una incursión al mundo islámico), y en Asia (el feudalismo japonés con el modo de producción asiático) ${ }^{5}$.

La discusión sobre el Estado elaborada desde la sociología empieza con los estudios de Max Weber, para quien el capitalismo va con el protestantismo (Weber, 2004). Las últimas sesenta páginas de Economía y sociedad llevan el nombre de "sociología del Estado", para distinguirla de la sociología de la dominación no legítima (Weber, 2008). Para este autor, el Estado (que es realmente "el Estado moderno") pertenece netamente al mundo europeo, pues al hablar del ancien régime chino señala que "un Estado con semejantes funcionarios es algo distinto del Estado occidental" (Weber, 2008, p. 1047), pues "la cosa es muy distinta en el Estado racional, el único en el que puede prosperar el capitalismo moderno" (Weber, 2008, p. 1048). Las condiciones sine qua non para que surja el capitalismo (que para Weber es sinónimo del mundo moderno) son la consolidación de las ciudades con su relativa autonomía, la producción fabril, una burocracia "racional" y un sistema de derecho adecuado.

En el discurso de Weber, al dejar de lado los Estados chino, japonés, feudal y otros "premodernos", hay algo de formalismo eurocéntrico, ya que busca "el Estado moderno secular y occidental" para estudiar "el Estado sin adjetivos", agregando algunos datos etnográficos. Para él, la racionalidad -que es un elemento central en todo su discurso- es instrumental y no existencial. Deja, así, de lado la posible coexistencia de diversas racionalidades, tal como lo planteó Lévy-Bruhl (admirado y citado por Evans-Pritchard, 1987). 
Tampoco se acerca a la idea de una "racionalidad del sistema", tal como lo indicara Maurice Godelier (1974). Con cierta razón Weber es considerado el padre (o abuelo) del individualismo metodológico que presentó Peter Winch en 1958 (Winch, 1972).

Otra idea que está presente en su inmensa producción sobre el Estado es "el uso legítimo de la fuerza física". Weber es, en gran medida, responsable de haber introducido el problema de la legitimidad en el discurso político, a usanza de la sabiduría popular de los argentinos, que distinguen entre "la dictadura y la dictasuave". Sin Weber no hay sociología del Estado, pero no toda la sociología del Estado es Weber.

La sociología nació a partir de la jurisprudencia y los jurisconsultas han jugado un papel muy importante en el desarrollo de una teoría del Estado. Una interesante crítica al derecho moderno viene de la pluma de un jurisconsulta argentino radicado en México:

[...] en este sentido, el Estado capitalista constituye la mediación entre el movimiento del capital global y el de los capitales individuales. La decisión política -el plan-, determinada en última instancia por las contradicciones sociales, se formaliza en el derecho económico para realizar la reproducción ampliada a escala global. El Estado se constituye, así, en una categoría del derecho económico. Es el deber de la circulación del capital (Correas, 2000, p. 279).

Otro estudio relevante, que combina una visión sociológica e histórica con una jurídica, es un libro acerca de lajusticia política, con elsubtítulo "empleo del procedimiento legal para fines políticos". En él se presenta un registro de diferentes definiciones del Estado: "la palabra Estado en este caso constituye solo una abreviatura para denominar una multitud de formas de organización pública, la polis, la res pública romana, el rey feudal, los feudos, la monarquía absoluta, los gobiernos constitucionales de los siglos dieciocho y diecinueve, la democracia popular y la sociedad totalitaria de masas" (Kirchheimer, 1968).

El mundo moderno es producto de una triple revolución que aconteció entre 1350, el año del fallecimiento de Guillermo de Ockham, y 1650, el año del fallecimiento de Descartes. En ese período el Renacimiento dotó al ser humano de una nueva sensibilidad y el nacimiento del capitalismo le entregó una nueva racionalidad, no solamente en lo económico, sino también en lo político, social e ideológico, además del descubrimiento mutuo del Nuevo Mundo y el viejo. Por primera vez en la historia de la humanidad apareció un mundo redondo y cerrado en el cual cabía la sociedad abierta.

El Estado moderno es implacable. Existen solamente dos tabicones primordiales: el Estado y el ciudadano. El Estado moderno y la sociedad moderna se distinguen de la sociedad tradicional y su Estado por varios rasgos: el Estado (y la sociedad) moderno es materialista, secular e individualista, mientras que la sociedad tradicional es mucho menos individualista y más colectivista, es religiosa y espiritual ${ }^{6}$.

Acercándonos al problema antropológico del Estado, y más específicamente a la formulación de una etnografía del Estado, ¿qué podemos decir? Una definición antropológica del Estado (se habla, por cierto, de "sistemas de Estado") plantea lo siguiente: "los Estados son formas de gobierno regional que se expanden dinámicamente por medio de la conquista" (Earle, 2000, p. 195). Esta definición nos enfrenta al problema de distinguir entre la conquista "externa" (desde fuera) y la conquista "interna" (desde dentro). 
Lo más importante que se ha dicho acerca del Estado en lo que se conoce como el Tercer Mundo o capitalismo periférico, es la declaración del sociólogo boliviano René Zavaleta (1989): "el Estado en la periferia es un Estado que no llena su territorio". La iniciativa privada, con la oleada neoliberal, lo que ha hecho, precisamente, es llenarlo.

\section{La etnografía}

Como señala Rosana Guber (2011), el término "etnografía" tiene dos significados: por un lado refiere al producto y corresponde, por lo tanto, a una descripción etnográfica; por el otro, refiere a la actividad, a la producción de la etnografía en su primer sentido, dimensión que adquiere mayor relevancia en el presente contexto.

La etnografía que abordamos aquí es mucho más amplia que la actividad de filigraneo que normalmente consideramos como la labor de los antropólogos de ir al campo. Gregory Bateson señala en las primeras páginas de su tesis Naven que:

Si fuera posible presentar de manera adecuada la totalidad de una cultura, con el énfasis que tiene cada elemento para los usuarios de la cultura misma, entonces ningún detalle le parecería bizarro, raro o arbitrario al lector, más bien se presentarían todos los detalles de una manera tan natural y razonable como lo es para los nativos que han pasado toda su vida dentro de la cultura en cuestión. Tal exposición se puede intentar mediante el uso de uno de dos métodos: por medio de técnicas científicas o artísticas. Por el lado artístico tenemos las obras de un pequeño puñado de hombres que no solamente han sido grandes viajeros $y$ observadores, sino también escritores de gran sensibilidad, hombres tales como Charles Doughty; y también tenemos representaciones espléndidas de nuestra propia cultura en novelas como las de Jane Austin o John Galsworthy. Por el lado científico tenemos las monografías detalladas y monumentales acerca de un pequeño número de pueblos $\mathrm{y}$, recientemente, las obras de Radcliffe-Brown, Malinowski y la Escuela Funcionalista (Bateson, 1958, p. 4).

Quisiera invocar uno de los descubrimientos que hizo Rivers en el proceso de nacimiento y desarrollo de la etnografía y del trabajo de campo en la tradición británica: la realización de un atlas etnográfico de su universo antropológico, el Pacífico o bien Melanesia. Intentó, por un lado, hacer etnografías minuciosas y precisas de un gran número de pequeñas islas, una por una, con lo que introdujo una especie de miopía antropológica, al prestar una máxima atención a los problemas de relaciones de parentesco. Por otro lado, presentó también un marco de la totalidad en una forma que podemos llamar "un marco de marco". Lamentablemente, formuló este "marco de marco" en uno de los idiomas del antievolucionismo británico, el difusionismo (formulado en la Universidad de Londres), lo cual lo marginó del universo antropológico, un universo muy denso y personal ${ }^{7}$. Creo que eso es uno de los problemas que debemos resolver para desarrollar una etnografía del Estado: encontrar un modelo que nos permita articular lo micro y lo macro, y esa es exactamente una de las virtudes de la Escuela de Manchester.

La etnografía nació en la antropología social británica en 1922 con las dos tesis fundacionales de Malinowski y Radcliffe-Brown. Sobre esto es justo emitir dos comentarios. En primer lugar, siempre se presenta la tesis de Malinowski como si hubiera salido de la nada y se olvida que Melanesia había sido estudiada con anterioridad, tal como lo plantea Stocking (1995): 
[...] el primero de la nueva generación de antropólogos con una formación académica que salió al campo fue Radcliffe-Brown, que fue a las islas Andamanesas en 1905. Pero por lo menos había otros nueve que emprendieron el estudio intensivo de un área limitada antes de la Gran Guerra. Gerald C. Wheeler de la London School of Economics y Arthur M. Hocart de Oxford acompañaron a Rivers en la expedición Percy Sladen Trust en 1908; Wheeler pasó diez meses entre los mono-alu en la parte occidental de las islas Salomón; Hocart se quedó cuatro años en Fiji, donde en su calidad de profesor de educación básica recogió un rico acervo de datos etnográficos. Diamond Jenness, estudiante de Oxford cuya hermana se había casado con un misionero en las islas D'Entrecasteaux, pasó nueve meses en la isla Goodenough en 1910, y luego hizo varios años de trabajo de campo entre los esquimales. Dos jóvenes finlandeses acompañaron a Westermarck a Inglaterra para trabajar bajo la tutela de Haddon: Gunnar Landtman salió en 1910 para pasar dos años en la isla Kiwa; Rafael Karsten trabajó entre tres tribus en el Chaco boliviano en 1911 y 1912. Y, a pesar de la idea de Haddon del "hombre científicamente formado", había dos mujeres que habían estudiado en Oxford: Barbara Freire-Marecco, quien trabajó entre los indígenas pueblo en el suroeste de los Estados Unidos, y María Czapliczka (como Bronislaw Malinowski, una emigrada polaca), que pasó un año bajo condiciones duras en el círculo ártico entre los tungus en 1914 (p. 200).

Pero, con toda la genialidad de esos dos padres fundadores, sus talentos iban en direcciones opuestas: Radcliffe-Brown era un pensador analítico que no contribuyó gran cosa al trabajo de campo y la etnografía, y Malinowski era un pensador entusiasta y poco sistemático, así que el fruto de esta fundación no se vería sino hasta la siguiente generación, con sus alumnos. Dicho con un poco de cinismo: solo la combinación de Radcliffe-Brown y Malinowski haría un antropólogo brillante. Por lo que, precisamente, sus alumnos constituyeron una generación sobresaliente: Evans-Pritchard, Meyer Fortes, Raymond Firth, S. F. Nadel y todo un grupo de mujeres extraordinarias: Mary Douglas, Audrey Richards, Monica Wilson, Elizabeth Colson, Lucy Mair, Phyllis Kaberry y Hortense Powdermaker, que lograron destacar, a pesar de que "el trabajo aplicado fue muchas veces considerado por los grandes mandarines como de menor exigencia intelectual y, por tanto, más adecuado para las mujeres" (Kuper, 1975, p. 136). A todo ese grupo hay que agregar a Max Gluckman y su Escuela de Manchester.

Es difícil expresar de qué manera nació la moderna antropología social británica. Del enfoque de Radcliffe-Brown, un estructuralismo empirista profundamente mecanicista, $y$ de la antropología de Malinowski, por cierto cultural y nada social, podemos afirmar que "no sería una exageración decir que la antropología de Malinowski creció a partir de su aplicación de una síntesis única del pensamiento de Ernst Mach y Nietzsche a los proyectos etnográficos de Frazer" (Thornton \& Skalnik, 1993, p. 5), a pesar de lo cual era un positivista y científico declarado.

Aventurándonos en otro terreno, podemos plantear la idea de que a partir de esas experiencias emerge el primer perspectivismo, que nace cuando un científico positivista declara, como punto de partida, que el único método científico válido es el método de las ciencias naturales (que invariablemente estudian objetos), pero descubre que sus objetos son sujetos. Ahí estamos ante la reflexividad.

Un punto de partida para adentrarnos en la etnografía del Estado es la declaración de que "un rasgo central del pasado de México y de América Latina ha sido la continua tensión entre las culturas populares emergentes y los procesos de formación del Estado" (Joseph \& Nugent, 2002, 
p. 31) pues, como señala Michel de Certeau, se puede hacer una distinción entre dos diferentes visiones de pensamiento, entre la visión táctica y la estratégica. La táctica es la visión desde abajo, mientras que la estratégica es la visión desde arriba (De Certeau, 1998, p. 45).

En su discusión sobre el Estado, Weber llamó la atención acerca de un punto medular en el intento por formular una etnografía del Estado: la necesidad de tomar en cuenta su funcionamiento diario. ¿De qué manera influye el Estado en la vida cotidiana? $Y$, al mismo tiempo, tener presente que esta vida cotidiana en el Estado es lo que contribuye a formar y cambiar el propio Estado.

Un último punto en nuestro viaje hacia una etnografía del Estado es considerar lo que podemos llamar "los usuarios del Estado". Estos son los que con sus actividades (y pensamientos) contribuyen a mantenerlo en funcionamiento. Finalmente, sería muy difícil discutir sobre el Estado sin considerar dos conceptos que colindan y permanentemente interactúan con él: la sociedad civil y la ciudadanía.

\section{El Estado en la Escuela de Manchester}

La Escuela de Manchester contribuyó al acervo de estudios políticos respecto de la relativa libertad del individuo dentro de la camisa de fuerza de la estructura social y el interés por el Estado y su estudio etnográfico.

Si aceptamos que la Escuela de Manchester nació en el momento de iniciarse la Segunda Guerra Mundial, en la entonces colonia británica de Rhodesia del Norte, podemos distinguir en los primeros textos de su fundador, Max
Gluckman (en su momento el director del Instituto Rhodes-Livingstone), una dialéctica que marcará los estudios sobre el Estado durante todos los años de su existencia, incluyendo la definición de la sociedad plural, el marco teórico de esta escuela.

El primer estudio de Max Gluckman es un conjunto de dos textos gemelos: por un lado, su contribución a Sistemas políticos africanos, en el cual estudia "la organización política zulú en dos períodos de su historia" (Gluckman, 2010, p. 91) y, por el otro, su largo artículo "Análisis de una situación social en el país zulú moderno" (Korsbaek, 2016c). En estos primeros trabajos, Gluckman echa por tierra la idea sostenida por la antropología social británica de que los nativos no tienen una historia, pues todo el texto es una detallada relación de las intrigas palaciegas:

Durante la vida de Shaka, los comerciantes se asentaron en Puerto Natal en términos amistosos con los zulú. Más tarde, los boers llegaron al Natal, conquistaron a los zulú en 1838 y los confinaron al norte del río Tugela. El gobierno de Dingane fue también tiránico y su gente empezó a apoyar a su hermano Mpande. Dingane urdió un plan para matar a Mpande y éste huyó con sus seguidores a los boers en Natal; de allí atacó y derrotó a Dingane y se convirtió en rey. Los zulú comenzaron entonces un período de relativa paz, pues Mpande sólo ocasionalmente atacaba a los swazi y tembe (thonga); al sur y al oeste estaban los estados europeos y los fuertemente atrincherados basuto. Sin embargo, durante su reinado dos de sus hijos pelearon por el trono; Cetshwayo triunfó y se convirtió en rey cuando Mpande murió en 1872. En 1880 los británicos derrotaron a los zulú, destituyeron a Cetshwayo y dividieron la nación en trece monarquías. Tres años después trataron de reinstalar a Cetshwayo; por varias razones la guerra civil estalló entre la sección Usuthu (la real) de la nación y de las tribus gobernadas, bajo el rey, por la casa de Mandlakazi Zulú, que se unió a la casa real en el periodo del abuelo Mpande. El rey murió pero su hijo Kinuzuzulo con los boer ayudó a derrotar a los rebeldes que huyeron con los británicos. En 1887 los británicos establecieron un magistrado en la tierra 
Zulú y restauraron a los Mandladazi a sus hogares. Dinuzulú resistió, fue derrotado y exiliado. Los zulú se dividieron en un número de tribus y el gobierno blanco se estableció firmemente. Dinuzulú fue designado jefe de una tribu pequeña (la Usuthu), pero fue nuevamente exiliado después de la rebelión de Bambade en 1906. Murió en exilio y su heredero fue nombrado jefe de los usuthu; después de su muerte fue reemplazado por su hermano como regente. El gobierno ha pasado de Inglaterra a Natal, y en 1910 pasó a la Unión de Sudáfrica (Gluckman, 2010, pp. 92-93).

Varios detalles llaman aquí nuestra atención. En primer lugar, que se trata de la historia de los zulú en su interacción con el Imperio británico y la población holandesa, los boer. En segundo lugar, que los nativos tienen nombre y apellido, no se trata de una población nativa anónima enfrentada a conquistadores con nombre. Finalmente, la relación de la lucha interna hace también a un lado la idea antropológica de que "donde empieza la familia termina la política". La descripción de la lucha y las intrigas puede compararse con la descripción de las intrigas en la corte japonesa descrita en Genji, de la señora Murasaki alrededor de 1000 d. C. (analizado por Alfred L. Kroeber, 1951), o en las sagas de Islandia, que tanto encantaban a Jorge Luis Borges y a Victor Turner.

En el siguiente resumen encontramos muchos de los elementos que, a través de los años, caracterizarían a la Escuela de Manchester:

La esencia de estos sistemas descritos es la oposición de otros grupos similares y la posibilidad de lealtades conflictivas del pueblo hacia sus diferentes autoridades. La nación era una organización estable, ya que esta oposición era principalmente entre las tribus que fueron adheridas a los puestos y los regimientos del rey. La rotación de la riqueza del gobernante era necesaria para poder mantener una relación cercana con su pueblo. El conflicto de lealtades a los oficiales de diferente rango, que frecuentemente intrigaban uno en contra del otro, se ventilaba como un llamado de aten- ción al desorden. Por lo tanto, a pesar de la aparente autocracia del rey y los jefes, el reinado del Estado residía en el pueblo. De cualquier modo, aunque un gobernante puede ser destronado, el sistema no es afectado. En la administración actual, las lealtades del pueblo y la competencia de los oficiales no estaban frecuentemente en conflicto, ya que el mecanismo administrativo trabajaba a través de diferentes tipos de grupos: la oposición principal provenía de los grupos similares, que cooperaban como parte de un grupo mayor (Gluckman, 2010, p. 128).

Vemos ahí el tema del conflicto, un eje que fue introducido en la antropología por Gluckman (Korsbaek, 2005). También destaca la idea del equilibrio móvil, a diferencia de la idea de los funcionalistas del equilibrio como el estado natural del mundo y cualquier desequilibrio como una anomia, en términos durkheimianos. Aparece, además, la raíz de la distinción entre "rebelión" y "revolución", que Gluckman habría heredado de Evans-Pritchard.

En el segundo de los dos textos iniciales, Gluckman aborda el Estado de manera amplia y generosa como una "sociedad plural":

La Unión de África del Sur es un Estado nacional habitado por 2.003.512 blancos, 6.597.214 africanos y miembros de varios otros grupos raciales ("colourgroups") ${ }^{8}$. No conforman una comunidad homogénea, pues el Estado es constituido principalmente por su división en grupos raciales de diferentes estatus. El sistema social de la Unión, en consecuencia, consiste en las relaciones interdependientes entre y dentro de los diferentes grupos raciales en cuanto grupos raciales (Gluckman, 1958, p. 1).

Se relata, también, el desarrollo histórico del Estado zulú antes de la llegada de los blancos:

[...] los zulu habían subyugado a pueblos que pertenecían más o menos a su propia cultura, por lo que su Estado era probablemente sin castas, mientras que 
pueblos nguni que huyeron de los zulu y conquistaron pueblos de una cultura ajena establecieron estados de castas, en los cuales el núcleo de aristócratas nguni se esforzaron por mantener su identidad. Eso sucedió en los Estados de Matalele, Andoni y Zángana. Dentro del Estado zulú, de una cultura homogénea, se podía hacer la organización sencillamente absorbiendo las tribus conquistadas bajo sus propios jefes, aunque Shaka y sus sucesores formaron nuevas tribus bajo parientes y favoritos. El linaje zulú, en gran medida descendientes de Mpande, el primer rey que tuvo hijos, se convirtió en un grupo real con un alto status, y los jefes (y en sus tribus, los linajes de los jefes) se encontraban también a un nivel arriba del de la gente común y corriente. Pero vivían, en términos generales, al mismo nivel. Las tribus tenían cierta autonomía y muy temprano dos de ellas se separaron de la nación. Sin embargo, la nación zulú se mantenía unida contra otros Estados bantú (y, más tarde, el Estado de los blancos). Durante unos pocos periodos intermedios, al extender sus fronteras, los zulúes hicieron incursiones contra naciones enemigas lejanas (Gluckman, 1958, p. 43).

Se discute, asimismo, con cierto detenimiento, el papel del Estado zulú en el mantenimiento del equilibrio político:

[...] entre las tribus continuaba existiendo un equilibrio de un jefe tribal contra otro; pues el jefe no era solamente una parte de la maquinaria administrativa en la cual representaba el poder del Estado, sino también el centro de la unidad de su tribu, situación que lo colocaba en una posición contra el Estado y contra otras tribus en el Estado. Dentro de una tribu, los parientes del jefe, o los hombres encargados de los distritos políticos, podían todavía ganar su independencia alejando a gente del lado del jefe, sujeto a la intervención del rey. Se sugiere que bajo las condiciones de comunicación a través del vasto territorio zulú, la nación quedara estable mientras sus tribus componentes estuvieran mutuamente hostiles. Un rey tiránico causaría que las tribus se unieran contra él, pero estas se quedaron unidas bajo la autoridad del rey para evitar que alguna tribu se volviera demasiado poderosa (Gluckman, 1958, p. 45).
En otro texto temprano de Gluckman (2009), el pequeño libro Cultura y conflicto en África, encontramos el Estado generosamente estudiado:

Los pueblos que llamamos primitivos varían desde pequeños grupos de cazadores, pescadores o recolectores de frutas silvestres, tales como los esquimales y los bosquimanos, hasta reinos africanos, como los casos de los zulú y los baganda. Aun los grandes Estados del África occidental, como los ashanti y Dahomey, son considerados primitivos en comparación con los Estados de Occidente. En estos Estados africanos grandes encontramos, a diferencia del caso de las comunidades más pequeñas, instituciones políticas más similares a las que encontramos en nuestras propias sociedades. Allí hay oficiales gubernamentales bien definidos y consejos con poderes ejecutivos, judiciales y legislativos que funcionan en un sistema de control y contracontrol con el cual estamos familiarizados. Nuestro interés general en estos Estados desarrollados es que presentan algunos de nuestros propios problemas políticos en una forma más sencilla. Pero un estudio de la manera en que las sociedades más primitivas, aquellas que carecen de instituciones gubernamentales, viven en unidad política, en una condición de paz y orden, nos abre nuevos campos de interés; y es sobre estos nuevos campos que me interesa antes que nada discutir. La conclusión más sorprendente de la moderna investigación antropológica es que la organización que se requiere para mantener el orden entre mil personas en una isla en el Pacífico es casi tan complicada como la que rige en una ciudad como Londres. La organización es complicada, aunque estas sociedades insulares, igual que muchas sociedades en África y en otras partes, no tienen un aparato cultural tan complicado como el nuestro: su equipo tecnológico es mucho más sencillo y la ausencia de relojes y calendarios le da un sabor alegre a su vida (p. 6).

Uno de los tratamientos más profundos en torno al Estado lo encontramos en la obra de Peter Worsley, que pertenece claramente a la Escuela de Manchester, sobre todo en dos de sus libros: The Trumpet Shall Sound, de 1957, y El tercer mundo, de 1964. En la introducción de ambos libros expresa su agradecimiento no solo 
a Gluckman, sino también a otros integrantes del clan Manchester, aunque él resulte un poco atípico, al menos en dos aspectos. En primer lugar, es sociólogo y no antropólogo. En 1970 publicó dos libros de Introduction to Sociology y, aunque uno de los libros, The Trumpet Shall Sound, se desarrolla en Melanesia y Nueva Guinea, donde es fácil seguir la pista de Joseph Conrad y perder la memoria del mundo occidental, mantiene el contacto sociológico con el mundo moderno y su Estado. En segundo lugar, a diferencia de la gran mayoría de los manchesterianos, no trabaja en África, sino -como ya se mencionó- en Melanesia y Nueva Guinea.

El Estado está claramente presente en su primer libro, The Trumpet Shall Sound, que trata de "el surgimiento de un gran número de curiosos movimientos religiosos en el sur del Pacífico durante las últimas décadas; en esos movimientos un profeta anuncia la inminencia del fin del mundo en un cataclismo que destruirá todo. Luego regresan los ancestros, o Dios o algún otro poder libertador, trayendo todas las mercancías que desean las gentes, e instalando un reino de bendición eterno" (Worsley, 1970, p. 21 , introducción a la primera edición de 1957).

Las primeras palabras en el libro revelan un rasgo, que funciona como marca registrada de la Escuela de Manchester: "este libro fue escrito con la firme convicción de que la antropología puede ser interesante a los no especialistas. $\mathrm{Si}$ los practicantes no siempre han logrado eso, hay que aceptar que algunos aspectos del tema son más atractivos que otros. Así que, por ejemplo, es difícil que el no especialista derive mucha satisfacción de las complicaciones del parentesco algebraico de los aborígenes australianos" (Worsley, 1970, p. 21).
Palabras que hacen eco de las de su maestro, Gluckman, en el libro Costumbre y conflicto en África: "los textos que conforman el libro fueron presentados originalmente en la primavera de 1955, bajo la forma de charlas populares en la radiodifusión británica $\mathrm{BBC}$, como una introducción popular a la antropología y sus particulares problemas en el mundo moderno" (Korsbaek, 2009b, p. 9).

El Estado es, como en otros tantos casos del imperialismo temprano y el colonialismo maduro, el Estado europeo imperial y encarna al enemigo: "Inglaterra, Alemania, Francia, Holanda y Australia habían dividido entre ellas toda esa región en el movimiento que sucedió después de 1880 , por un lado con vista a la potencialidad económica, pero también con la intención de establecer bases estratégicas. Los efectos de este impacto europeo fueron devastadores" (Worsley, 1970, p. 26). En esta relación histórica, el Estado europeo es omnipresente, aunque "movimientos similares han ocurrido en todas las partes del mundo, aún en la historia de Europa, y no se limitan de ninguna manera a pueblos y tierras lejanos" (Worsley, 1970, p. 21).

Todavía más clara es la presencia del Estado en el segundo libro, en el cual introduce el concepto de tercer mundo para reflexionar en torno a los efectos del Primer Mundo sobre los pueblos y los sistemas políticos del Tercer Mundo en el marco del colonialismo y el imperialismo. En el capítulo III, "Variedades de la experiencia revolucionaria", crea una tipología de tres diferentes formas de respuesta revolucionaria: 1) movimientos surgiendo de lazos culturales (religiosos, lingüísticos, étnicos, etc.) anteriormente existentes; 2) movimientos que tienen su origen en decisiones políticas europeas, basados en el tema de una ciuda- 
danía compartida (donde los connacionales tal vez no comparten una misma cultura, pero "tienen el mismo destino colonial"), y 3) movimientos supranacionales, tales como el paneslavismo, el panislamismo y el panafricanismo (Worsley, 1964, p. 91-111).

Ambos libros pertenecen a una tradición etnográfica inaugurada por Eric Hobsbawm en sus primeros trabajos, dedicados a la descripción de las características culturales y las causas y consecuencias sociales de los movimientos de protesta, tanto individuales como colectivos, de preferencia en el Mediterráneo y América Latina, tales como Rebeldes primitivos, de 1959 (Hobsbawm, 1968), y Bandits, de 1969, continuados en Revolucionarios, de 1973 (ídem, 1978), que marca su transición de antropólogo a historiador (si es que en verdad sea necesario marcar una diferencia). Los dos libros tienen también parentesco con el libro En pos del milenio. Revolucionarios milenaristas y anarquistas místicos de la Edad Media, de Norman Cohn (1981), que espacialmente da el salto de Melanesia a Europa y, en el tiempo, de los años "después de 1880" a los siglos XI-XIV.

Jaap Van Velsen, uno de los estudiantes que confirman la estrecha relación existente entre los antropólogos (y sociólogos) holandeses con la Escuela de Manchester, ha sido fundamental en la introducción de lo que podemos llamar "la libertad humana" (que tiene mucho que ver con "rational choice") en el análisis de las instituciones. Desarrolló también el método del caso extendido en el campo de la antropología jurídica (Van Velsen, 1967) y se acercó al Estado en su tesis doctoral acerca de la manipulación del sistema de parentesco entre los tonga en África (Van Velsen, 1964), una investigación en la cual inevitablemente entró en contacto con el tema y que tiene mayor relevancia en el tema que estamos revisando.

En la obra de Victor W. Turner, la más hermenéutica de la Escuela de Manchester, aparece el Estado sobre todo en su desarrollo del concepto del drama social, tanto en su tesis doctoral como en su uso en el análisis de la lucha de Hidalgo por la independencia de la Nueva España de la vieja España.

En el primer capítulo de Schism and Continuity in an African Society, la tesis doctoral de Turner, se presenta "el trasfondo histórico y ecológico" y la condición geográfica: "la jefatura de Kanongesha está virtualmente dividida en dos por la frontera entre Angola y Rhodesia, y a cada lado de la frontera hay un jefe que se llama Kanongesha y como tal es reconocido por el poder colonial" (Turner, 1996, pp. 1-2). El proceso histórico y político de esta pequeña comunidad no se desarrolla sin la intervención del Estado (el poder colonial británico), pues cuando el gobierno británico intentó abolir el oficio de jefe ndembu de Nyakeseya en 1947, el ocupante del oficio se dirigió a prisa a Mwantiyanvwa, que le escribió, en nombre del jefe, una carta al comisionado de la provincia occidental. Como resultado este fue reinstaurado en su oficio (Turner, 1996).

Todo el proceso político, el drama social, en el mundo indígena de los ndembu sucede en un diálogo dialéctico no solamente con el gobierno colonial británico, sino con otras condiciones macro, como el tráfico de esclavos:

Los ndembu también me contaron que antes de la llegada de los europeos, los ndembu solían hacer incursiones contra otros ndembu para capturar miembros del otro grupo y venderlos a los comerciantes de esclavos 
Ovimbundo, y así adquirir rifles, pólvora y tela. En tiempos de conflicto, una aldea grande era una unidad más efectiva en términos de expediciones de asalto y defensa que una aldea pequeña (Turner, 1996, p. 229).

De la misma manera, en el texto sobre la lucha de Hidalgo contra el Estado imperial español, Turner analiza a los actores de ese drama social:

Entre las categorías de "actores" encontramos a españoles, criollos europeos, criollos americanos, mestizos e indios. En la Nueva España, en tiempos de Hidalgo, los criollos americanos compitieron con los criollos españoles y europeos por las posiciones superiores en el Estado, el ejército y la Iglesia; los mestizos y los indios se encontraban en conflicto con los españoles y con muchos criollos por el acceso y el derecho a la tierra. Por otro lado, los criollos que compitieron entre ellos por los oficios y la autoridad tuvieron un interés compartido por conservar muchos rasgos del sistema de distribución de los recursos. De nuevo, muchos criollos, igual que los españoles, estaban dispuestos a defender el sistema colonial, y eran incluso capaces de persuadir o influenciar a muchos mestizos e indios a compartir esta orientación. Al contrario, un número limitado de criollos americanos, muchos mestizos y un gran número de indios, estaban dispuestos a socavar el orden normativo constituido por el sistema de Estado-Iglesia del México español (Turner, 2016 pp. 30-31).

El punto más alto en la etnografía del Estado en la Escuela de Manchester es probablemente la producción de Bruce Kapferer. El Estado está presente desde sus primeros trabajos. En 1969 se doctora con una tesis dirigida por Clyde Mitchell, una investigación en África en el marco del Instituto Rhodes-Livingstone (allí Kapferer pudo presenciar la agonía de esta institución), con un tema bastante típico de la Escuela de Manchester: Strategy and Transaction in an African Factory: African Workers and Indian Management in a Zambian Town, tal como reza el título de la versión publicada (Kapferer, 1969). En esta investigación, Kapferer estudia un conflicto en una fábrica en Zambia, propiedad de hindúes, con trabajadores africanos que provienen de aldeas y regiones tribales, pero que tienen que ganarse la vida como trabajadores asalariados. Esto en el marco de un conflicto entre el difunto gobierno colonial y el nuevo Estado independiente.

Aunque la enorme producción académica de Kapferer incluye elementos tan exóticos como la religiosidad popular, los mitos y los sistemas no occidentales de medicina y curación, el Estado está presente en prácticamente todos sus textos: tanto en $A$ Celebration of Demons. Exorcism and the Aestetics of Healing in Sri Lanka (Kapferer, 1983) como en The Feast of the Sorcerer. Practices of Consciousness and Power (Kapferer, 1988). En "The Aporía of Power" advierte contra el Estado corporativo señalando que "la mera institución del Estado es ampliamente concebida como inseparable de la guerra. Si constituye la paz dentro de las fronteras o el orden de su soberanía, esta misma paz puede ser la precondición de su potencial para la guerra contra los otros Estados que se encuentran fuera" (Kapferer, 2004, p. 64).

En su introducción a Oligarchic Corporations and New State Formations llama la atención sobre uno de los rasgos del Estado en el neoliberalismo (Kapferer, 2005):

Las actuales configuraciones del poder global, imperial y del Estado refieren a formaciones de control oligárquico. Un rasgo fundamental de eso es el control de organizaciones e instituciones políticas por parte de grupos sociales densamente tejidos (familias o dinastías de familias, grupos de parentesco, asociaciones cerradas o redes de personas estrechamente interrelacionadas) para fines de un control relativamente exclusivo de recursos económicos y de su distribución, siendo esos recursos vitales para grandes poblaciones (p. 163). 
Una de las virtudes de Kapferer (2009) es que no toma en serio la promesa de la secularidad del Estado moderno:

En muchos casos, los agentes y las agencias del Estado fueron capaces de excitar un grado de religiosidad en los ideales nacionalistas - con frecuencia con resultados desastrosos y trágicos. A pesar de la religiosidad de muchos nacionalismos, por lo regular se presentaba como explícitamente secular, evitando un compromiso abierto con la religión (p. 1).

Pero, ¿cómo trata este autor el Estado en su etnografía? Creo que el lugar idóneo para seguir el tratamiento práctico-teórico que Kapferer desarrolla es su clásico estudio del nacionalismo, en el cual compara audazmente a este en dos Estados tan diferentes como lo son Sri Lanka y Australia, pues el primero está inserto en el capitalismo periférico y el segundo en el capitalismo central (1988, p. XXXVII).

Un elemento omnipresente en su relato es la violencia: "las metáforas de reconstrucción cósmica y restauración personal en el Suniyama, así como en todos los exorcismos, son violentas. Su violencia es generada por el choque de las grandes fuerzas de contradicciones cósmicas que abarcan el destino del mismo cosmos, del Estado y de la persona. Sin embargo, la violencia de su destrucción y reformación en la Auniyama termina logrando una última trascendental ecuanimidad, armonía y paz" (Kapferer, 1988, p. 76). Palabras que nos recuerdan los planteamientos de Gluckman en Rituales de rebelión (Gluckman, 1954).

Creo que no hay un enfoque más avanzado en la etnografía del Estado que la versión que conocemos desde la etnografía desarrollada por Kapferer.

\section{Conclusiones}

En un intento por formular una conclusión quisiera limitarme a señalar dos puntos. Podemos concluir, en primer lugar, que el Estado es omnipresente y que una etnografía del Estado es importante, desde muchos puntos de vista.

El Estado se ha convertido en uno de los vehículos más relevantes del nacionalismo. Sobre el peso de este tenemos una expresión gráfica en el fútbol profesional: los equipos británicos, franceses, alemanes y españoles están llenos de jugadores africanos y, cuando estos son presentados, siempre se menciona si vienen de Ghana, Nigeria o de dónde sea, pero nunca se dice de a qué tribu, grupo étnico o grupo lingüístico pertenecen. La nacionalidad se ha vuelto una especie de etiqueta de la identidad tanto individual como colectiva.

Pero este problema es doblemente complicado, pues en el desenfrenado proceso de globalización, en el cual la nacionalidad ya está perdiendo su relevancia, sigue siendo la etiqueta más segura. Este sello está íntimamente relacionado con el Estado y, a pesar del proceso de marginación que sufren tanto el uno como la otra, las banderas nacionales siguen siendo un indicador gráfico de primera importancia. Uno de los especialistas en el estudio del Estado ha expresado la paradoja de la omnipresencia de este y su creciente marginación: "el Estado habla cada vez más fuerte, pero parece estar diciendo y haciendo cada vez menos" (Joseph, 2002, p. 15).

La etnografía del Estado es importante pues para llegar más allá de la visión normativa que muchas veces tienen los sociólogos y, sobre todo, los especialistas legales, necesi- 
tamos información empírica y, como he intentado mostrarlo, solamente la etnografía puede presentar una imagen de las colectividades y relacionarla con el proceso de toma de decisiones, que sigue siendo un asunto individual -aunque a veces mediado por un proceso político.

Al margen del proceso de marginación del Estado y de la nación, tenemos en nuestras manos una complicación que convierte la necesidad de entenderlo en una urgencia: el surgimiento del Estado Islámico, con sus acciones contundentes recientes en territorios fuera de los Estados árabes -en el sentido tradicional de Estado, territorio, pueblo y lengua-, en España, Francia, Inglaterra y Bélgica.

El Estado posee una dinámica que se deja captar por un acercamiento científico, casi como si fuera una máquina. Pero, al mismo tiempo, tiene también un fuerte contenido histórico: no es lo mismo el Estado británico y el Estado francés que el Estado mexicano. Y la especificidad histórica del Estado es importante en el momento de pretender acercarse a él en América Latina, por una razón muy específica: gran parte del interés de los antropólogos por esta entidad se concentra en su carácter compuesto, un carácter que tiene mucho que ver con su origen en el capitalismo periférico.

Lo mismo sucede en África. El Estado en la periferia -para utilizar esta expresión- debe su origen al proceso de descolonización, que ha sido mencionado en varios lugares en este texto. Pero es importante tener en mente que el proceso de descolonización que produjo las nuevas repúblicas africanas es un proceso que fue iniciado al terminar la Segunda Guerra Mundial y que, en cierta medida, sigue hoy en día, mientras que el proceso de descolonización que produjo las repúblicas en América Latina inició con la debacle del Imperio español, tal como se ve en el texto de Victor Turner de Hidalgo.

Ya que los chistes políticos con frecuencia dicen más acerca de lo que consideramos como la realidad, permítaseme terminar con un chiste acerca del Estado Islámico: se dice que el representante de la Casa Blanca en alguna ocasión declaró que nosotros -los Estados Unidos- no negociamos con Estados como el Estado Islámico, solamente los financiamos. 


\section{Notas}

${ }^{1}$ El presente texto fue presentado, en inglés, como ponencia en The Conference of the Commission on Theoretical Anthropology of the International Union of Anthropological and Theoretical Sciences, que se celebró en Cracovia, Polonia, del 7 al 9 de agosto de 2016. Este ensayo no es más que una serie de apuntes para una investigación en proceso. La meta inmediata es la elaboración de un libro acerca de la Escuela de Manchester, en el que una buena parte de sus capítulos ya han sido publicados o están siendo publicados como artículos en diversas revistas de ciencias sociales (Korsbaek, 2016a, 2016b, 2016c, 2016d, 2018).

${ }^{2}$ En Korsbaek (1999) se encuentra una discusión sobre lo que es la antropología, con una serie de definiciones de la disciplina y pistas para extender la búsqueda de la identidad de nuestra ciencia. Teniendo en mente los notables avances teóricos que la antropología tuvo durante tiempos de guerra, y citando las palabras iniciales de Ruth Benedict: "Los japoneses eran el enemigo más extraño con el que los Estados Unidos nunca se hubieran enfrentado en un conflicto total. En ninguna otra guerra con un enemigo considerable había sido necesario tener en mente costumbres tan exageradamente diferentes de actuar y pensar" (Benedict, 1946, p. 1), se podría pensar en definir a la antropología como

\section{Referencias bibliográficas}

Abrams, Ph. (1988). Notes on the Difficulty of Studying the State. Journal of Historical Sociology, 1(1), marzo, 58-89.

Anderson, P. (1979). Transiciones de la antigüedad al feudalismo. México: Siglo XXI.

(1980). El Estado absolutista. México: Siglo XXI.

Bateson, G. (1958). Naven. The Culture of the latmul People of New Guinea as Revealed through a Study of the Naven Ceremony, $2^{-}$ ed. Stanford: Stanford University Press. (Naven, análisis de un ritual iatmul. Barcelona: Jucar, 1990).

Benedict, R. (1946). The Chrysanthemum and the Sword. Nueva York: Charles E. Tuttle \& Co.

Bourdieu, P. (1994). "Rethinking the State: Genesis and Structure of the Bureaucratic Field". Sociological Theory, 12(1). pp. 1-18.

Brown, R. (1973). Anthropology and Colonial Rule: The Case of Godfrey Wilson and the Rhodes-Livingstone Institute, Northern Rhodesia. En Asad, T. (Ed.), Anthropology and the Colonial Encounter, pp. 173197. Nueva York: Humanity Books.

Certeau, M. de (1998). La invención de lo cotidiano. 1. Artes de hacer. México: Universidad Iberoamericana.

Cohn, N. (1981). En pos del milenio. Revolucionarios milenaristas y anarquistas místicos de la Edad Media. Madrid: Alianza.

Correas, Ó. (2000). Introducción a la crítica del derecho moderno (Esbozo). México: Fontamara.

Douglas, M. (1959). Review: W. Watson. Tribal Cohesion in a Money Economy. Man, 59(270), 168. "el estudio de las costumbres de los enemigos, tanto reales como virtuales".

${ }^{3}$ Una relación de la creación del Instituto Rhodes-Livingstone se encuentra en Korsbaek (2016a).

${ }^{4}$ Una interesante discusión sobre el dilema de Godfrey Wilson se encuentra en un capítulo (Brown, 1973) del libro de Talal Asad acerca del imperialismo.

${ }^{5}$ Esta obra es una continuación de otro estudio histórico de "transiciones de la antigüedad al feudalismo" (Anderson, 1979).

${ }^{6}$ Hace unos años escribí una tesis de maestría en filosofía, bajo la dirección de Ramón Xirau, acerca de esas características del mundo moderno, resultado de lo que llamé "la revolución moderna". He publicado solamente un artículo histórico-filosófico acerca de este mundo moderno (Korsbaek, 2008), pero toda mi antropología gira en torno a la cuestión de la modernidad y su convivencia con el mundo tradicional.

${ }^{7}$ Rivers era un brillante pensador y trabajador de campo, pero hoy está casi por completo olvidado, injustamente. Algunas informaciones se encuentran en Korsbaek (2014) y existe una discusión interesante sobre él en Hviding \& Berg (2014).

8767.984 eurafricanos-eurasiáticos (coloured), 219.928 asiáticos. Las cifras son del Censo de 1936, Preliminary Report U. G. 50/1936.

Earle, T. (2000). Estado, sistemas de. En Barfield, T. (Ed.), Diccionario de antropología, pp. 195-196. México: Siglo XXI.

Evans-Pritchard, E. E. (1987). Historia del pensamiento antropológico. Madrid: Cátedra.

Forster, P. (1973). Empirismo e imperialismo. Una revisión de la crítica de la antropología social por la nueva izquierda. En D. Goddard, J. Banaji \& Peter Forster, Crítica de la antropología británica, Barcelona, Cuadernos de Anagrama.

Gluckman, M. (1954). "Rituals of Rebellion in Southeast Africa", en Max Gluckman: "Order and Rebellion in Tribal Africa", New York, The Free Press, 1963: 110-136 (org. la Conferencia Frazer, Universidad de Glasgow, el 28 de abril de 1952).

(1958). Analysis of a Social Situation in Modern Zululand, Manchester, University of Manchester Press (Análisis de una situación social en el país zulú moderno. Trad. de Leif Korsbaek, L., Vivar Quiroz, K. \& Baroco Gálvez, M. F., rev. de Barrios Luna, M. Manuscrito). (2009). Costumbre y conflicto en África. Trad. de Korsbaek, L. \& Leong Fu, S. K., Introd. de Korsbaek, L. Lima: Universidad de Ciencias y Humanidades, Universidad de San Marcos.

(2010). El reino zulú de Sudáfrica. En Fortes, M. \& EvansPritchard, E. E. (Eds.), Sistemas políticos africanos, pp. 91-130. Trad. de Korsbaek, L. \& Díaz Pineda, H. M.. México: Centro de Investigaciones y Estudios en Antropología Social, Universidad Autónoma MetropolitanaIztapalapa, Universidad Iberoamericana..

Godelier, M. (1974). Rationalité et irrationalité en économie, I-II. 
París: Maspero.

Guber, R. (2011). La etnografía. Método, campo y reflexividad. Buenos Aires: Siglo XXI.

Hobsbawm, E. (1968). Rebeldes primitivos. Estudio sobre las formas arcaicas de los movimientos sociales en los siglos XIX y XX. Barcelona: Ariel.

(1969). Bandits. Harmondsworth: Penguin Books.

(1978). Revolucionarios. Ensayor contemporaneous.

Barcelona: Ariel.

Hviding, E. \& Berg, C. (Eds.) (2014). The Ethnographic Experiment. A. M. Hocart and W. H. R. Rivers in Island Melanesia, 1908. Nueva York, Oxford: Berghahn Books.

Joseph, G. M. (2002). "Prólogo". En Joseph, G. M. \& Nugent, D. (Comps.), Aspectos cotidianos de la formación del Estado, pp. 11-16. México: Era.

Joseph, G. M. \& Nugent, D. (2002). Cultura popular y formación del Estado en el México revolucionario. En Joseph, G. M. \& Nugent, D. (Comps.), Aspectos cotidianos de la formación del Estado, pp. 3152. México: Era.

Kapferer, B. (1969). "Norms and Manipulations of Relationships in a Work Context", en J. Clyde Mitchell, ed.: Social Networks in Urban Situations, Manchester, Manchester University Press, 1969. pp. 120-156. (1983). A Celebration of Demons. Exorcism and the Aesthetics of Healing in Sri Lanka, Bloomington, Univesity of Indiana Press. (1988). Legends of People, Myths of State. Washington: Smithsonian Institution Press.

(2004). Introduction. Old Permutations, New Formations? War,

State and Global Transgression. Social Analysis, 48(1), primavera, 64-72. (2005). Introduction: Oligarchic Corporations and New State

Formations. Social Analysis, 49(1), primavera, 163-176.

(2009). Religiosities toward a Future. In Pursuit of the New

Millennium. Social Analysis, 53(1), primavera, 1-16.

Kierkegaard, S. (1906). Om begrebet ironi (en danés: "acerca del concepto de ironía"). En Kierkegaard, S., Samlede Vaerker, Tomo XIII, pp. 93-394. Copenhague: Gyldendal.

Kirchheimer, O. (1968). Justicia política. Empleo del procedimiento legal para fines políticos. México: Unión Tipográfica Editorial Hispano Americana.

Korsbaek, L. (1999). La antropología y sus disciplinas vecinas. Ciencia Ergo Sum, 6(1), 76-82 \& 6(2), 176-182.

(2005). El estudio antropológico del conflicto en la antropología mexicana. El caso de San Francisco Oxtotitlpan, una comunidad indígena en el Estado de México. Estudios Latinoamericanos (Universidad Nanzan, Nagoya, Japón), No. 2: 28-46.

(2008). La revolución moderna: la escritura, la lectura y la modernidad. Cinteotl, (3), marzo 2008, pp. 1-26.

(2009a). La etnografía de una comunidad matlatzinca en el Estado de México. El sistema de cargos y la neoetnicidad en San Francisco Oxtotilpan, Municipio de Temascaltepec. (Tesis inédita de doctorado). Universidad Autónoma Metropolitana-Iztapalapa, México. (2009b). Introducción. En Gluckman, M., Cultura y conflicto en África, pp. 9-27. Lima: Universidad de Ciencias y Humanidades, Universidad de San Marcos.
(2014). W. H. R. Rivers: médico, psicólogo, etnólogo y antropólogo británico, y en todo carismático. Cuicuilco, 21(9), 41-64.

(2016a). La prehistoria de la Escuela de Manchester: el Instituto Rhodes-Livingstone en el centro-sur de África. Estudios de Asia y África, 51(1), 197-234.

(2016b). La Escuela de Manchester y el estudio del derecho. Alegatos, (92), 531-556.

(2016c). El método de la Escuela de Manchester. Del análisis situacional al drama social. Boletín de Antropología Americana, 1(1). pp. 79-101.

(2016d). Los estudios de la política en la Escuela de Manchester. Alma Máter, 4(3), pp. 75-88.

(2018). La Escuela de Manchester. Colonialismo británico en África, en el marco del estado de bienestar. Anales de Antropología, Vol. 52-1. pp. 99-109.

Kroeber, A. L. (1951). The Novel in Asia and Europe. University of California Publications in Semitic Philology, XI, 233-241.

Kuper, A. (1975). Antropología y antropólogos. La Escuela Británica, 1922-1972. Barcelona: Anagrama.

Lindholm, Ch. (2000). Douglas, Mary (1921). En Barfield, T. (Ed.), Diccionario de antropología, pp. 173-174. México: Siglo XXI.

MacDonald, T. (2000). Sociedades plurales. En Barfield, T. (Ed.), Diccionario de antropología, pp. 490-491. México:

Moore, B. (1973). Los orígenes sociales de la dictadura y la democracia. Barcelona: Península.

Nadel, S. F. (1955). Fundamentos de la antropología social. México: Fondo de Cultura Económica.

Stocking, G. W. (1995). After Tylor. British Social Anthropology 1888-1951. Madison: University of Wisconsin Press.

Thornton, R. J. \& Skalnik, P. (Eds.) (1993). The Early Writings of Bronislaw Malinowski. Cambridge: Cambridge University Press.

Turner, V. W. (1996). Schism and Continuity in an African Society. A Study of Ndembu Village Life. Oxford, Washington: Berg.

(2016). Hidalgo: la historia como drama social. La Pacarina del Sur, (26), abril-junio. Trad. de Korsbaek, L.

Van Velsen, J. (1964). The Politics of Kinship. A Study of Social Manipulation among the Lakeside Tonga. Manchester: Manchester University Press.

(1967). The Extended Case Method and Situational Analysis.

En Epstein, A. L. (Ed.), The Craft of Social Anthropology, pp. 129-149. Londres: Tavistock.

Weber, M. (2004). La ética protestante y el espíritu del capitalismo. Introd. y ed. crítica de Gil Villegas, F. México: Fondo de Cultura Económica. (2008). Economía y sociedad. México: Fondo de Cultura Económica.

Winch, P. (1972). Ciencia social y filosofía. Buenos Aires: Amorrortu.

Worsley, P. (1970). The Trumpet Shall Sound. A Study of Cargo Cults in Melanesia. Londres: Paladin Books.

(1964). El tercer mundo. Una nueva fuerza vital en los asuntos internacionales. México: Siglo XXI.

Zavaleta, R. (1989). El estado en América Latina, La Paz, Editorial Los Amigos del Libro. 